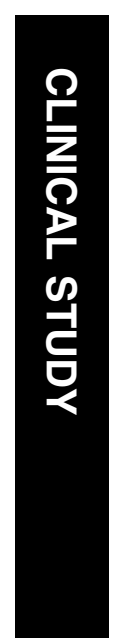

${ }^{1}$ SB Ankara Eye Hospital, Ankara, Turkey

\section{${ }^{2}$ Department of} Ophthalmology, University of Kara Elmas School of Medicine, Zonguldak, Turkey

${ }^{3}$ Departments of Ophthalmology, University of Pittsburgh School of Medicine, Pittsburgh, PA, USA

${ }^{4}$ Department of Pathology, University of Pittsburgh School of Medicine, Pittsburgh, PA, USA

Correspondence: F Koc, Kuzgun sok 48/3, Asagi Ayranci Ankara 06540, Turkey Tel: +90 3124687459 ; Fax: + 903123124827 . E-mail: dr_feray@ yahoo.com

Received: 25 April 2005 Accepted in revised form: 17 September 2005 Published online: 11 November 2005

The authors and their families have no proprietary interest in any material used in this study

This study was conducted in University of Pittsburgh School of Medicine, Pittsburgh, Pennsylvania, USA

\title{
The aetiology in paediatric aphakic glaucoma
}

\begin{abstract}
Purpose To investigate the causes of glaucoma in children following removal of cataracts.

Methods In total, 24 patients (37 eyes) with uncomplicated congenital cataracts who developed glaucoma following cataract removal were studied retrospectively. Cataract morphology, surgical technique, postoperative complications, time to glaucoma onset, gonioscopic findings, the presence of microcornea, and the histopathologic characteristics of the filtration angle in one case were the studied parameters.

Results We found a bimodal onset of glaucoma. Early-onset glaucoma occurred at a mean age of 6 months in 15 eyes and delayedonset glaucoma at a mean age of 12 years in 22 eyes. Early-onset glaucoma was significantly $(P=0.018)$ more likely to be due to angle closure. With delayed-onset glaucoma, the filtration angle is open in $86 \%$ of eyes and significantly $(P=0.006)$ more eyes in the delayed-onset group had microcornea.

Conclusions Performing cataract surgery very early in life in microphthalmic eyes and leaving residual lens material increases the risk for glaucoma. We recommend a prophylactic iridectomy in eyes at risk for pupillary block. Eyes with delayed-onset glaucoma have open filtration angles but with findings consistent with incomplete development of filtration structures. Early age at cataract extraction and microcornea are risk factors for delayed-onset glaucoma.
\end{abstract}

Eye (2006) 20, 1360-1365. doi:10.1038/sj.eye.6702150; published online 11 November 2005

Keywords: Congenital cataract surgery; aphakia; glaucoma

\section{Introduction}

Glaucoma is one of the most serious complications following cataract surgery in
F Koc ${ }^{1}$, S Kargi ${ }^{2}$, AW Biglan ${ }^{3}$, CT Chu ${ }^{3,4}$ and

JS Davis ${ }^{3}$ children. ${ }^{1-13}$ Pupillary block with subsequent closure of the filtration angle has been identified as one of the causes. ${ }^{14,15}$ Although pupillary block occurs less often with use of contemporary surgical techniques and instruments, glaucoma continues to be a difficult, and potentially blinding complication of cataract surgery. ${ }^{4,5,7,8,11}$ The other form of glaucoma that has been recognized has an open angle configuration. The precise cause for the increased intraocular pressure in open-angle glaucoma in aphakic children remains unclear.

The purpose of this study is to investigate the causes and characteristics of glaucoma after cataract surgery in young children with the goal to identify changes in care that could be implemented in an effort to reduce this vision threatening complication.

\section{Patients and methods}

This study was approved by the Institutional review board and consent was taken from the participants and their parents.

We reviewed the clinical records over a 25-year span, of all children in our paediatric ophthalmology practice who were diagnosed with glaucoma that occurred after cataract surgery. All cataracts were identified before 1 year of age, and removed before 5 years of age. Patients were excluded if they had (1) a history of increased intraocular pressure (IOP) before cataract surgery, (2) signs of congenital glaucoma, (3) conditions other than cataract that might predispose to development of glaucoma such as rubella or persistent hyperplasic primary vitreous (PHPV), (4) syndromeassociated cataracts, or (5) cataracts related to trauma.

A diagnosis of glaucoma was established by having at least two of the following criteria:

(1) repeated IOP measurements over $21 \mathrm{mmHg}$;

(2) cupping of the optic nerve consistent with glaucoma and (3) increasing corneal diameter, 
(4) visual field loss and (5) an excessive myopic shift in the refractive error.

The following data were recorded: cataract morphology, age at cataract surgery and corneal diameter, central corneal thickness, laterality of glaucoma, surgical technique used to remove the cataract, the number and type of secondary procedures, primary or secondary insertion of an IOL, visual fields, age at the time of glaucoma diagnosis, and histopathologic findings of one eye that was enucleated.

$\chi^{2}$ and Mann-Whitney $U$-tests were used for statistical analysis.

\section{Results}

We identified 24 patients (37 eyes) who developed glaucoma after cataract surgery. Patient characteristics are summarized in Tables 1 and 2.

\section{Onset of glaucoma}

The onset of glaucoma after cataract surgery followed a bimodal pattern (Figure 1). There were 15 eyes that had an early onset of glaucoma (1 week to 13 months after cataract surgery), and a second group, 22 eyes that had a delay in onset (70-177 months after cataract surgery). In all, 13 patients had bilateral cataract surgery and developed bilateral glaucoma, In 10 of these cases the onset of the glaucoma was well correlated in both eyes. Two patients with bilateral aphakia developed earlyonset glaucoma due to pupillary block in the first eye and delayed-onset open-angle glaucoma in the fellow eye. And one case developed late-onset open-angle glaucoma in both eyes with a time interval of almost 2 years. Three patients had bilateral cataract surgery but developed unilateral glaucoma. Seven of the remaining eight patients had unilateral cataract surgery and unilateral

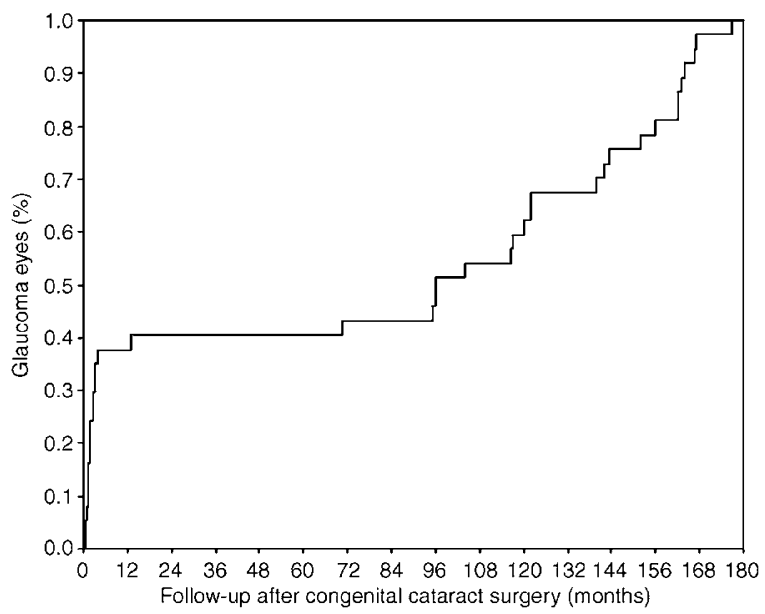

Figure 1 Kaplan-Meier survival curve showing percentage of eyes developing glaucoma as a function of time since congenital cataract surgery. Note the bimodal pattern of onset.

Table 1 Characteristics of early-onset $v$ s delayed-onset glaucoma

\begin{tabular}{|c|c|c|c|}
\hline Patients characteristics & Early-onset group & Delayed-onset group & Total \\
\hline No. of patients & 11 & 15 & 24 \\
\hline No. of eyes & 15 & 22 & 37 \\
\hline Gender M/F & $4 / 7$ & $6 / 9$ & $10 / 14$ \\
\hline Unilateral/bilateral & $7 / 4$ & $8 / 7$ & $11 / 13$ \\
\hline Age at $\mathrm{GO}^{a}$ & $0.5(0.08-1.1)$ & $12(6-15)$ & $10(0.08-15)$ \\
\hline Interval CS and $\mathrm{GO}^{\mathrm{a}}$ & $0.16(0.02-1.08)$ & $11.75(5.8-14.75)$ & $8(0.02-14.75)$ \\
\hline Total follow-up ${ }^{a}$ & $15(4-24)$ & $16(3-25)$ & $16(3.00-25)$ \\
\hline Follow-up after $\mathrm{GO}^{\mathrm{a}}$ & $14.50(3.25-23.75)$ & $4.25(1-15)$ & $8(1-23.75)$ \\
\hline
\end{tabular}

$\mathrm{M}=$ male; $\mathrm{F}=$ female; $\mathrm{GO}=$ glaucoma onset; $\mathrm{CS}=$ cataract surgery.

${ }^{\mathrm{a} M e d i a n}$ value in years.

Table 2 Characteristics of early-onset and delayed-onset glaucoma

\begin{tabular}{lccr}
\hline Characteristics & Early-onset group $(n=15)$ & Delayed-onset group $(n=22)$ & $P$-value \\
\hline Microcornea & 1 & 11 & 0.006 \\
Cataract-type N/C/L/AP/PP/? & $5 / 1 / 1 / 2 / 0 / 6$ & $7 / 6 / 5 / 2 / 1 / 1$ & 0.509 \\
Median age at cataract surgery (months) & $3(0.25-11)$ & $3.75(0.25-60)$ & 0.143 \\
OL implantation & 2 & 4 & 0.532 \\
Pupillary block & 8 & 3 & 0.009 \\
Angle closure $>270$ & 7 & 3 & 0.018 \\
\hline
\end{tabular}

$\mathrm{IOL}=$ intraocular lens; $\mathrm{L}=$ lamellar; $\mathrm{N}=$ nuclear; $\mathrm{PP}=$ posterior polar; ? = unknown. 
glaucoma and the sixth patient, developed primary open angle glaucoma in the phakic eye at age 21. Early-onset glaucoma typically had an abrupt onset. Presenting symptoms and signs were pain, photophobia, lacrimation, pupillary block, angle closure, rapid myopic shift in the refractive error, and corneal oedema. Delayed-onset glaucoma (in 18 of 22 eyes) had an insidious, painless onset with an increased IOP that was discovered on routine examination.

\section{Microcornea}

The corneal diameters were classified as either microcornea or normal-size cornea for the child's age by comparing them to Wallace and Plager's ${ }^{16}$ table of ageadjusted normal corneal diameters in children. Twelve of $37(32 \%)$ eyes were found to have microcornea, and it was found to be highly associated with delayed-onset open-angle glaucoma $\left(P=0.006, \chi^{2}\right)$.

\section{Lens morphology}

Data related to lens morphology were available for 17 patients. The most common cataract type was nuclear. Twelve eyes had this form of cataract, and they were equally distributed in the early-onset (33\%) and delayedonset $(32 \%)$ groups. $\left(P=0.509, \chi^{2}\right)$.The remaining cataracts were: complete, lamellar, anterior polar, and posterior polar.

\section{Cataract procedures}

The surgical technique for cataract removal was aspiration of the lens material in 20 eyes (nine in the early-onset group and 11 in the delayed-onset group) and aspiration combined with posterior capsulectomy and anterior vitrectomy in 17 eyes (six in the early-onset group and 11 in the delayed-onset group) Patients who had simple aspiration of the lens material had significantly more often required secondary procedures (19 of the 20 eyes) to treat posterior capsule opacification, retained lens material, or pupillary block comparing to the patients who had also primary posterior capsulectomy and anterior vitrectomy (three of the 17 eyes) $\left(P<0.001, . \chi^{2}\right)$.

A peripheral iridectomy or iridotomy had been performed in only five eyes during cataract surgery (two eyes in early-onset group and three eyes in the late-onset group). A Pupil block mechanism did not occur in any of them. However, in eyes that did not have a peripheral iridectomy, pupillary block was a frequent reason for early-onset glaucoma (eight of 13) compared to those with delayed onset of glaucoma (three of 19 eyes) $\left(P=0.007, \chi^{2}\right)$.

\section{Gonioscopic findings}

Of 37 eyes, 33 underwent gonioscopic examination during the follow-up period. The filtration angle was found to be closed in at least three quadrants at the time of diagnosis of glaucoma in 10 eyes: seven in the earlyonset group and three in the delayed-onset group $\left(P=0.018, \chi^{2}\right)$.

Localized peripheral anterior synechiae (PAS) over a few clock hours, flat iris insertion, poorly developed angle recess, a sheet of translucent tissue overlying the meshwork, and increased pigmentation over the trabecular meshwork, narrow or invisible ciliary band, an indistinct scleral spur, and increased vasculature, sometimes bridging the angle, were the most consistent gonioscopic findings in the remaining 23 eyes (Figure 2).

\section{Visual fields and pachymetry}

Five (eight eyes) patients had reliable visual fields; five eyes had an arcuate scotoma or nasal step and three eyes had full visual fields. Measurement of the central corneal thickness was performed in eight patients (11 eyes) with delayed-onset open-angle glaucoma and all had central corneal thickness greater than $545 \mu \mathrm{m}$.

\section{Histopathology}

Figure 3 shows the findings of an angle in an eye of a patient with delayed-onset glaucoma; the meshwork was compact and hypercellular, the iris stroma and neovascular tissue encroaches on the partially developed

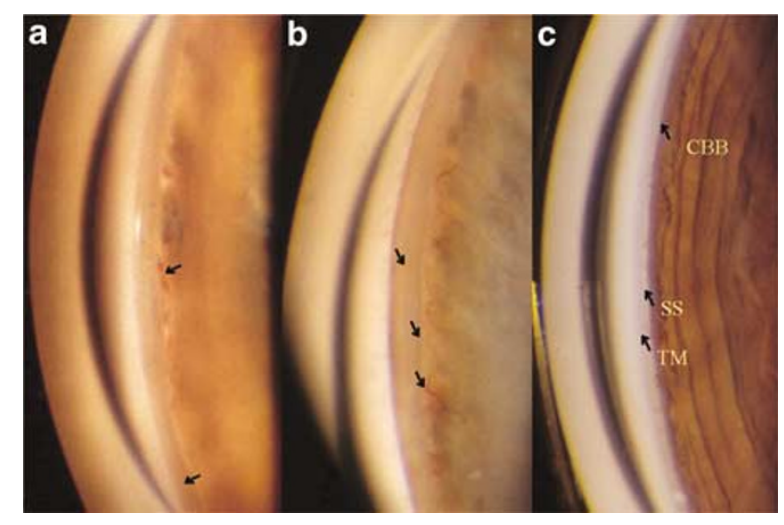

Figure 2 (a) and (b); Gonioscopic appearance of two eyes with microcornea and delayed-onset aphakic glaucoma. Note the high iris insertion, lack of angle recess, no undulation on iris surface, visible iris vessels and the pigmented membranous tissue covering the angle. The scleral spur (SS) is indiscriminate. Trabecular meshwork (TM), cilliary body band (CBB). (c) Gonioscopic appearance of an age-matched eye with congenital nuclear cataract and microcornea. Note the normal appearance of iris, CBB, SS and TM. 

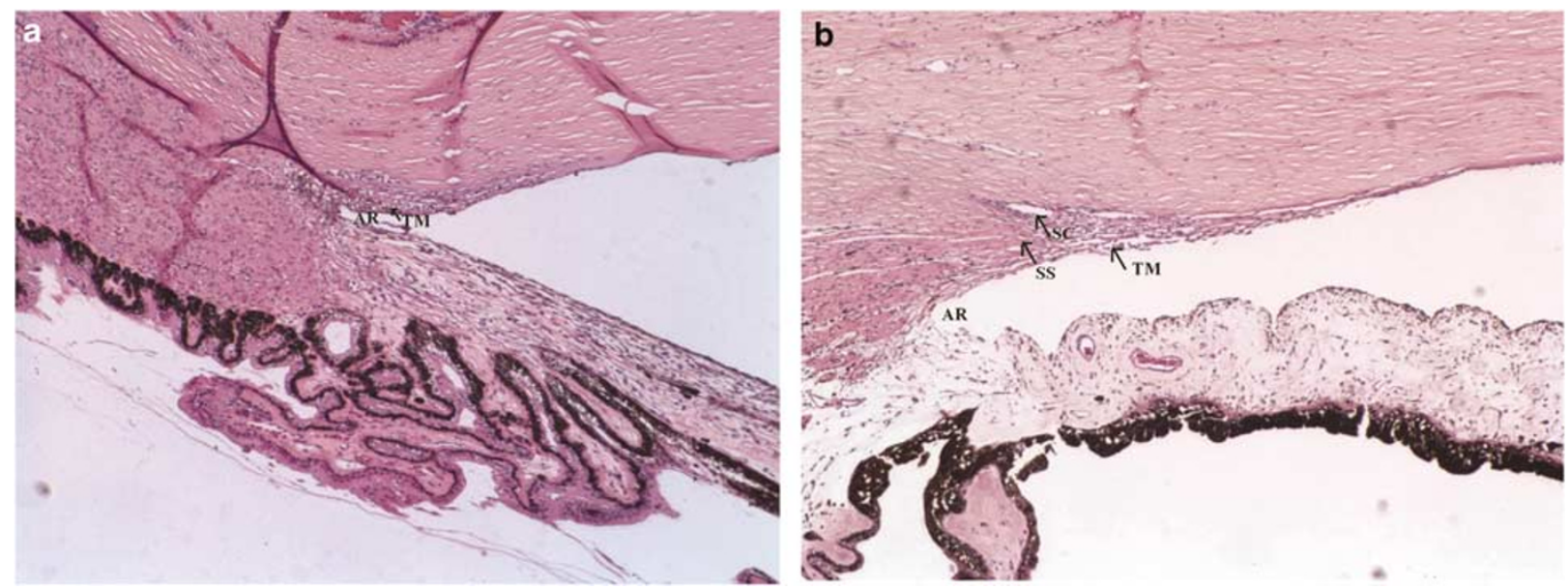

Figure 3 (a) Histopathologic view of an angle with delayed-onset aphakic glaucoma. There is no identifiable SC, the SS is indistinct, and the TM is compact. The angle recess is poorly developed, and a neovascular membrane covers the TM. H\&E, $\times 4$. (b) An agematched normal filtration angle.

angle recess, the lumen of Schlemm's canal could not be clearly identified. Pigmented cells, including iris stromal cells, melanophages, and rare siderophages, were present in the filtration angle.

\section{Discussion}

In an effort to learn more about the factors specific to the development of glaucoma after cataract surgery, we studied a select group of children who had cataract surgery, but excluded eyes with cataracts and associated conditions that might predispose to the development of glaucoma.

\section{Onset and mechanism of glaucoma}

The onset of glaucoma had a bimodal pattern of distribution. (Figure 1) The results of our study reaffirm the observations of Mills and Robb ${ }^{7}$ who also showed a bimodal pattern of onset of glaucoma following cataract surgery in children. They also noted that glaucoma with an angle-closure mechanism frequently occurs within the first few months after surgery and open-angle glaucoma has a later onset (average 7.4 years). As the mechanism causing glaucoma is different, we feel this classification is useful. Chen $e a^{11}$ did not observe a bimodal pattern of onset of glaucoma. The filtration angles were open in 94 $\%$ of their patients. In our study group, $54 \%$, of eyes with early-onset glaucoma and $15 \%$ of the eyes with delayedonset glaucoma had angle-closure.

Simon $e t a l^{5}$ reported that open angle glaucoma occurs after a latent period of 5.5 years following cataract surgery in children. Asrani and Wilensky ${ }^{9}$ reported an average interval between cataract surgery and the onset of open-angle glaucoma of 12.2 years. In our study, with a mean follow-up time of 15.3 years, open-angle glaucoma developed between 6 and 14 years after cataract surgery. The longer the patients are followed after cataract surgery, the longer the time for onset of open-angle glaucoma. Children who have undergone cataract surgery have a continuing risk to develop glaucoma throughout their lives. ${ }^{2,5,8,9,11,13,17,18}$

\section{Timing and role of cataract surgery in glaucoma development}

Cataract surgery within the first year of life has been identified as a risk factor for glaucoma. $3,7,10,11,12$ This was obvious in our aphakic glaucoma series also; $92 \%$ of cataracts were removed before 1 year and $27 \%$ were removed before 1 month of age. Rabiah ${ }^{13}$ found an incidence of glaucoma of $37 \%$ if the cataract surgery was performed before 9 months, and this was reduced to $14 \%$ if the surgery was performed between 9 months and 2 years of age, and only $9 \%$ if performed between 2 and 3 years of age.Vishwanath $e a^{12}$ found that after bilateral lensectomy within the first month of life, a 5-year risk of developing glaucoma in at least one eye was $50 \%$ and it decreased to $14.9 \%$ if surgery performed later in the first year.

The timing of cataract surgery in infants may have to be reassessed. Prompt removal of congenital cataracts is considered to be important to achieve good visual and functional results. ${ }^{19,20}$ However, early surgery increases the risk for glaucoma. Vishwanath $e t \mathrm{al}^{12}$ have suggested to delay the surgery until the infant is 4 weeks old in bilateral cases, and after review of our findings, we also recommend delaying cataract surgery for children with bilateral complete cataracts until 1 month of age for a full-term child. 
Mori $e t a l^{21}$ reported 58 eyes of 41 patients with congenital cataracts that were not surgically removed. During a mean follow-up of 19 years, only two eyes developed glaucoma; in both cases, glaucoma was of the angle-closure-type-related to PHPV. There are three reports of patients with bilateral congenital cataracts, but only one of the eyes was operated upon. ${ }^{2,5,7}$ In these patients, glaucoma developed only in the surgically treated eyes. Thus, glaucoma in children with cataracts seems to be clearly related to surgery to remove the cataracts.

Early-onset glaucoma is clearly related to the surgical procedure to remove the cataract. In this study, pupil block with secondary angle closure was found to be the principal cause of early-onset glaucoma. Mills and $\mathrm{Robb}^{7}$ made similar observations. Residual lens material contributes to development of glaucoma by forming Elschnig pearls that mechanically block the pupil and induces inflammatory adhesions in the angle and at the pupil edge which can cause papillary block and angle closure. ${ }^{2,8,14,15}$ In our study, residual proliferating lens material were required to be removed later in eight eyes. The conversion from assisted aspiration to ocutomeenhanced aspiration combined with posterior capsulectomy and anterior vitrectomy has enabled the surgeon to remove lens cortex and capsule more effectively. This has been reduced, but not eliminated, the prevalence of pupillary block and subsequent angle closure. In eyes that have poor pupil dilatation or when technical problems occur that preclude complete removal of the cortex, we recommend performing an iridectomy.

We found that sulcus fixation of the IOL is a risk factor for the development of pupillary block. Others have also made this observation. ${ }^{7,22-23}$ In three of the six eyes in which the IOL was fixed in the sulcus, pseudophakic pupillary block developed. We recommend placement of the IOL within the capsular bag whenever possible. If this is unable to be accomplished, we recommend performing a peripheral iridectomy.

\section{Microcornea}

Microcornea is one of the risk factors for glaucoma that cannot be altered. The association between microcornea and development of glaucoma has been reported. ${ }^{7,9,10-}$ 12,13,16 Parks et $\mathrm{al}^{6}$ found a 33\% incidence of glaucoma in eyes operated on that had a corneal diameter less than $10 \mathrm{~mm}$. The prevalence of microcornea among aphakic glaucoma patients is as high as $88.5 \%{ }^{6}$ to $94 \% .{ }^{16}$ In our population, age-adjusted microcornea was present in only $7 \%$ of eyes with early-onset glaucoma but it was present in $50 \%$ of eyes with delayed-onset glaucoma. Smaller eyes and eyes with reduced corneal diameter have a predisposition for angle closure. However, no eye with microcornea developed angle-closure glaucoma in our population; all of them had open-angle glaucoma.

Microcornea may account for the abnormally thick corneas seen in 11 eyes in this study. The increased thickness may cause the measured IOP to seem higher than it actually is. Although many eyes in our study with glaucoma had thick corneas, we felt that the changes observed in the optic nerve cup and the visual field changes and occasional spikes in IOP over $40 \mathrm{mmHg}$. meant that these eyes had glaucoma and not ocular hypertension.

\section{Possible mechanisms for delayed-onset open-angle glaucoma}

Mori $e t a l^{21}$ suggested that the aphakic state of the eye that follows the operation may be responsible for the glaucoma.The lens has a volume in the eye and has dynamic functions related to its role in accommodation, which is more prominent at younger eyes. The surgical removal of it early in life can alter normal development of the filtration angle. Morphologic studies of developing eyes of children have shown that the angle recess of the iridocorneal angle is expected to move toward the periphery, exposing the scleral spur, and the ciliary body band. ${ }^{24-25}$ Our study, and that of Walton, ${ }^{8}$ and Keech et $a l^{4}$ show that there is altered development of the filtration angle. Eyes with delayed-onset open-angle glaucoma had an open angle but, there was anterior insertion of the iris and lack of development of the angle recess and filtration structures compared to adults. In the enucleated eye we examined, we observed anterior displacement of iris tissue with incomplete development of the angle recess. The trabecular meshwork was compact and thickened. These findings, and the changes observed on gonioscopy, suggest that there is a relative arrest in the normal development of the filtration angle and the trabecular meshwork in the eyes of aphakic children.

Altered accommodation mechanism related to the loss of lens may have a role in the functioning of the filtration angle also. During accommodation, the longitudinal fibers of the ciliary muscle, which are inserted in the scleral spur, contract. This expands Schlemm's canal and opens the interstices of the trabecular meshwork, which increases aqueous outflow. ${ }^{26-30}$ Parasympathomimetic drugs stimulate the ciliary muscle which puts traction on the trabecular sheets and separates the trabecular sheets. These agents simulate accommodation and they are effective in lowering the pressure in aphakic eyes. 


\section{Conclusions}

Early-onset glaucoma after cataract surgery in children is usually of the angle-closure type secondary to pupillary block. Preventable risk factors for early-onset glaucoma include early cataract surgery, not performing an iridectomy when there is retained lens material after cataract extraction, a pupil that dilates poorly, a shallow anterior chamber, and sulcus fixation of an IOL.

Delayed-onset glaucoma usually occurs years after surgery and is usually of the open-angle type. As a result of the late onset of this form of glaucoma, it is probably not directly linked to the procedure itself. Eyes with delayed-onset glaucoma have filtration angles that on gonioscopy appear to be open but with findings consistent with incomplete development of filtration structures. Early age at cataract extraction and microcornea are risk factors for delayed-onset glaucoma.

\section{References}

1 Chandler PA. Surgery for congenital cataract. Am J Ophthalmol 1968; 65: 663-673.

2 Phelps CD, Arafat NI. Open-angle glaucoma following surgery for congenital cataracts. Arch Ophthalmol 1977; 95: 1985-1987.

3 Chrousos GA, Parks MM, O'Neill JF. Incidence of chronic glaucoma, retinal detachment and secondary surgery in pediatric aphakic patients. Ophthalmology 1984; 91: 1238-1241.

4 Keech RV, Tongue AC, Scott WE. Complications after surgery for congenital and infantile cataracts. Am J Ophthalmol 1989; 108: 136-141.

5 Simon JW, Mehta N, Simmons ST, Catalano RA, Lininger LL. Glaucoma after pediatric lensectomy/vitrectomy. Ophthalmology 1991; 98: 670-674.

6 Parks MM, Johnson DA, Reed GW. Long-term visual results and complications in children with aphakia: A function of cataract type. Ophthalmology 1993; 100: 826-841.

7 Mills MD, Robb RM. Glaucoma following childhood cataract surgery. J Pediatr Ophthalmol Strabismus 1994; 31 : 355-360.

8 Walton DS. Pediatric aphakic glaucoma: A study of 65 patients. Trans Am Ophthalmol Soc 1995; 93: 403-420.

9 Asrani SG, Wilensky JT. Glaucoma after congenital cataract surgery. Ophthalmology 1995; 102: 863-867.

10 Magnusson G, Abrahamsson M, Sjostrand J. Glaucoma following cataract surgery: An 18-year longitudinal follow-up. Acta Opthalmol Scand 2000; 78: 65-70.

11 Chen TC, Walton DS, Bhatia LS. Aphakic glaucoma after congenital cataract surgery. Arch Ophthalmol 2004; 122: $1819-1825$
12 Vishwanath M, Cheong-Leen R, Taylor D, Russel-Eggit I, Rahi J. Is early surgery for congenital cataract a risk factor for glaucoma? Br J Opthalmol 2004; 88: 905-910.

13 Rabiah P. Frequency and predictors of glaucoma after pediatric cataract surgery. Am J Ophthalmol 2004; 137: 30-37.

14 Eustis SH, Walton RC, Ball SF. Pupillary block glaucoma following pediatric cataract extraction. Ophthalmic Surg 1990; 21: 413-415.

15 Pressman SH, Crouch ER. Pediatric aphakic glaucoma. Ann Ophthalmol 1983; 15: 568-573.

16 Wallace DK, Plager DA. Corneal diameter in childhood aphakic glaucoma. J Pediatr Ophthalmol Strabismus 1996; 33: 230-234.

17 Egbert JE, Wright MM, Dahlhauser KF, Keithahn MA Letson RD, Summers GC. A prospective study of ocular hypertension and glaucoma after pediatric cataract surgery. Ophthalmology 1995; 102: 1098-1101.

18 Johnson CP, Keech RV. Prevalence of glaucoma after surgery for PHPV and infantile cataracts. J Pediatr Ophthalmol Strabismus 1996; 33: 14-17.

19 Cheng KP, Hiles DA, Biglan AW, Pettapiece MC. Visual results after early surgical treatment of unilateral congenital cataracts. Ophthalmology 1991; 98: 903-910.

20 Hosal BM, Biglan AW, Elhan AH. High levels of binocular function are achievable after removal of monocular cataracts in children before 8 years of age. Ophthalmology 2000; 107: 1647-1655.

21 Mori M, Keech RV, Scott WE. Glaucoma and ocular hypertension in pediatric patients with cataracts. JAAPOS 1997; 1: 98-101.

22 Brady KM, Atkinson CS, Kilty LA, Hiles DA. Glaucoma after cataract extraction and posterior chamber lens implantation in children. J Cataract Refract Surg 1997; 23(1): 669-674.

23 Vajpayee RB, Angra SK, Titiyal JS, Sharma YR, Chabbra VK. Pseudophakic pupillary-block glaucoma in children. Am J Ophthalmol 1991; 111: 715-718.

24 Tawara A, Inomata H, Tsukamoto S. Ciliary body band width as an indicator of goniodysgenesis. Am J Opthalmol 1996; 122: 790-800.

25 Shields MB. Primary congenital glaucoma. In: Brown CL,Vaughn VM, Knighten DL (eds). Textbook of Glaucoma, 3rd ed. Williams \& Wilkins: Baltimore, 1992 pp 220-235.

26 Kaufman PL. Accommodation. In: Hart W (ed). Adler's Physiology of the Eye; Clinical Application, 9th ed. St Louis: CV Mosby, 1992 pp 391-411.

27 Armaly MF. Studies on intraocular effects of the orbital parasympathetic pathway. I. Technique and effects on morphology. II. Effect on intraocular pressure. III. Effect on steady-state dynamics. Arch Ophthalmol 1959; 61: 14-29, 62: 117-124, 62: 817-827.

28 Allen L, Burian HM. The valve action of the trabecular meshwork. Am J Opthalmol 1965; 59: 382-389.

29 Coleman DJ. Unified model for accommodative mechanism. Am J Opthalmol 1970; 69: 1063-1079.

30 Coleman DJ, Fish SK. Presbyopia, accommodation, and the mature cataracts. Ophthalmology 2001; 108(9): 1544-1551. 